\title{
Contribuição da matéria orgânica na fertilidade do solo
}

\author{
Rafael Vinícius de Arruda ${ }^{a}$, Victória Pontes Damasceno Araújo ${ }^{a}$, Selma Barboza Campos ${ }^{a}$, Konrad Kroker \\ Rempto $^{a}$, Giovanna Oliveira dos Santos ${ }^{a}$ \\ aGraduados em Agronomia pela Universidade de Cuiabá (Unic), MT, Brasil.
}

RESUMO Sistemas conservacionistas de manejo quando bem executado, podem apresentar um expressivo efeito na melhoria da qualidade de solos. Este trabalho tem como objetivo apresentar vantagens da utilização da matéria orgânica em contribuição às propriedades químicas do solo. A matéria orgânica (M.O) provém, em quase sua totalidade, dos organismos vegetais e, sua composição varia entre diferentes espécies vegetais e animais. Aproximadamente $95 \%$ do $\mathrm{N}$ e do $\mathrm{S}$ e $60 \%$ a $80 \%$ do $\mathrm{P}$ totais do solo estão localizados na matéria orgânica e são dependentes do processo de mineralização para serem absorvidos pelas plantas. Contudo, a matéria orgânica pode proporcionar maior produção de ácidos orgânicos no meio, consequentemente melhorar a fertilidade e sustentabilidade agrícola.

PALAVRAS-CHAVE: conservacionista; húmus; solos

Aceito 09 de setembro de 2019 Publicado online 16 de setembro de 2019

Cite este artigo:

Arruda et al. (2019) Contribuição da matéria orgânica na fertilidade do solo. Multidisciplinary Reviews 2: e2019020, DOI: 10.29327/multi.2019020

\section{Organic matter contribution to soil fertility}

ABSTRACT Conservation management systems, when well executed, can have a significant effect on soil quality improvement. This work aims to present the advantages of the use of organic matter in contribution to the chemical properties of the soil. Organic matter (M.O) comes almost from plant organisms and its composition varies between different plant and animal species. Approximately $95 \%$ of $\mathrm{N}$ and $\mathrm{S}$ and $60 \%$ to $80 \%$ of total soil $\mathrm{P}$ are located in organic matter and are dependent on the mineralization process to be absorbed by plants. However, organic matter can provide higher production of organic acids in the environment, consequently improving fertility and agricultural sustainability.

KEYWORDS: conservationist, humus, soils

\section{Introdução}

O tipo de solo e de condições climáticas é responsável pelo aumento da matéria orgânica do solo em sistemas conservacionistas de manejo e os mesmos têm reflexos na qualidade física e química do solo. E com esse aumento, vindo da prática conservacionista de incorporação de adubos orgânicos, aumenta os estoques e a estabilidade de agregados, sendo a magnitude deste efeito dependente do tipo de solo e condições climáticas (Balesdent et al 2000).

Sistemas conservacionistas de manejo quando bem executado, podem apresentar um expressivo efeito na melhoria da qualidade de solos tropicais e subtropicais. Mesmo que em pequenas frações, a matéria orgânica tem influência sobre a agregação do solo, devido tratar-se de uma fonte mais facilmente assimilável de $\mathrm{C}$ e de energia pelos microrganismos heterotróficos, cujos compostos do metabolismo microbiano atuam na estabilização de macro agregados de solo (Costa et al 2004). Assim, este trabalho tem como objetivo apresentar vantagens da utilização da matéria orgânica em contribuição às propriedades químicas do solo.

\section{Matéria orgânica}

A matéria orgânica (M.O) provém, em quase sua totalidade, dos organismos vegetais e, sua composição varia entre diferentes espécies vegetais e, dentro da mesma espécie, com a idade da planta e animais existentes no solo. Ela 
pode ser definida como todo material orgânico, vegetal ou animal (liteira, biomassa microbiana, fragmentos de resíduos, compostos solúveis e matéria orgânica ligada intimamente aos argilominerais do solo) (Stevenson 1994).

O material da qual ela se origina, é dependente da vegetação a qual está inserida. A fragmentação orgânica do solo constitui um sistema muito complexo em que se encontram os resíduos das plantas e animais em vários graus de decomposição, produtos excretados pelos organismos vivos e produtos de síntese originados à custa dos anteriores; micro-organismos vivos que de acordo com os autores Roscoe e Machado (2002), não é possível distinguir e separar do material orgânico morto.

Mesmo apresentando diferenças entre as espécies, ocorre certa constância entre os componentes básicos das plantas, variando o percentual dos constituintes estruturais. Segundo Waksman (1936), em termos de percentuais de peso do vegetal seco, os componentes dos vegetais são comumente, divididos em seis grandes grupos: (1) Celulose (1560\%); (2) Hemicelulose (10-30\%); (3) Lignina (5-30\%); (4) Fração solúvel em água (5-30\% incluindo açúcares, aminoácidos e ácidos alifáticos; (5) Fração solúvel em éter ou em álcool (1-15\% incluindo gorduras, óleos e ceras) e (6) Proteínas (1-10\%). Entretanto, Dick et al (2009), reportam que 90\% da estrutura da MOS é composta de carbono, oxigênio, nitrogênio (em média 55, 34, 3 e 5\%).

\section{Matéria orgânica e propriedades químicas do solo}

Se tratando dos atributos químicos do solo influenciados pela M.O destacam-se a disponibilidade de nutrientes para as culturas, a CTC e a complexação de elementos tóxicos e de micronutrientes, fundamentais em solos tropicais, altamente intemperizados e ácidos (Salton 2008). Com isso, a matéria orgânica é considerada uma fonte fundamental de nutrientes às plantas, disponibilizando elementos essenciais tais como $\mathrm{N}, \mathrm{P}$ e $\mathrm{K}$, por serem estes nutrientes seus constituintes fundamentais (Barilli 2005).

Aproximadamente $95 \%$ do $\mathrm{N}$ e do S e $60 \%$ a $80 \%$ do $\mathrm{P}$ totais do solo estão localizados na matéria orgânica e são dependentes do processo de mineralização para serem absorvidos pelas plantas. E a mineralização é necessária para a liberação destes nutrientes e é também responsável pela redução do estoque de matéria orgânica (Loss et al 2009). Boa parte dos nutrientes apresenta interação com a matéria orgânica, induzindo a ciclagem e adsorção destes elementos, e dessa forma, evitando com que ocorram perdas por lixiviação por conta da liberação gradativa às plantas em curto espaço de tempo (Bronick e Lal 2005).

Se tratando dos micronutrientes, a formação de complexos com compostos orgânicos ajuda aumentando e disponibilizando mais elementos às plantas. A complexação de Zn e Cu por ácidos orgânicos de baixo peso molecular é um exemplo de aumento e disponibilização de elementos. A formação de complexos também é responsável pela diminuição da disponibilidade de alumínio (Al) e manganês ( $\mathrm{Mn}$ ), fazendo com que aconteça a redução da toxidade às plantas, através da complexação destes elementos com substancias húmicas e ácidos orgânicos simples (Souza 2012).

\section{Interação da matéria orgânica no solo}

As interações acontecem devido à alta quantidade de cargas dos grupos funcionais da matéria orgânica, que influenciam de forma significativa a capacidade de troca catiônica (CTC) e ponto de carga zero (PCZ), porque as interações da matéria orgânica são fundamentais para solos tropicais, já que grande parte destes são ácidos e altamente intemperizados em alguns casos, dependendo do teor de matérias orgânica, da classe textura e da mineralogia, a matéria orgânica do solo pode representar entre 20 a $90 \%$ da CTC (Canellas et al 2003).

De acordo com Canellas et al (2003), a relevância da matéria orgânica para com a CTC do solo e, de modo consequente, em outras características químicas do solo relacionadas ocorre pela geração de cargas provenientes da matéria orgânica mais humificadas, chamada de substancias húmicas. Essas substâncias apresentam alta superfície específica comparada com as argilas dos solos de regiões tropicais e subtropicais, constituídos principalmente por óxidos de ferro (Fe) Al e por filossilicatos 1:1, cujas superfícies possuem baixa concentração de grupos funcionais de carga negativa.

Ainda com relação ao seu efeito na CTC, a matéria orgânica ajuda no aumento do poder-tampão do solo devido à presença de ácidos fracos presentes (carboxílicos e fenólicos) o que minimiza as variações na reação do solo. 
Recordando que o poder-tampão de um solo é avaliado através da maior ou menor dificuldade com que se consegue mudar seu pH (Dobbss 2008).

\section{Considerações finais}

Contudo, com relação à manutenção dos resíduos vegetais no manejo do solo, a matéria orgânica pode proporcionar maior produção de ácidos orgânicos que irão atuar diretamente na biologia do solo, tratando-se de uma fonte energética (carbono orgânico) para os microrganismos. Quanto maior for o teor de carbono orgânico de um material, maior será a fonte nutricional para a atividade microbiológica e maiores serão os benefícios no meio, consequentemente melhorar a fertilidade e sustentabilidade agrícola.

\section{Referências}

Balesdent J, Chenu C, Balabane M (2000). Relação da dinâmica da matéria orgânica do solo com a proteção física e preparo do solo. Pesquisa do solo e lavoura 53:215-230.

Barilli J (2005) Atributos de um Latossolo Vermelho sob aplicação de resíduos de suínos. Tesis, Universidade Estadual Paulista.

Bronick CJ, Lal R (2005). Estrutura e manejo do solo: uma revisão. Geoderma 12:3-22.

Canellas LP, Velloso ACX, Marciano CR, Ramalho JFGP, Rumjanek VM, Rezende CE, Santos GDA (2003) Propriedades químicas de um Cambissolo cultivado com cana-de-açúcar, com preservação do palhiço e adição de vinhaça por longo tempo. Revista Brasileira de Ciência do Solo 27:935-944.

Costa FDS, Bayer C, Albuquerque JA, Fontoura SMV (2004) Aumento de matéria orgânica num Latossolo Bruno em plantio direto. Ciência Rural 34:587-589.

Dobbss LB, Canellas LP, Alleoni LRF, de Rezende CE, Fontes MPF, Velloso ACX (2008) Eletroquímica de Latossolos brasileiros após a remoção da matéria orgânica humificada solúvel. Revista Brasileira de Ciência do Solo 32:985-996.

Loss A, Pereira MG, Schultz N, Anjos LD, Silva ED (2009) Carbono e frações granulométricas da matéria orgânica do solo sob sistemas de produção orgânica. Ciência Rural 39:1077-1082.

Pigatin LBF (2011) Compostos orgânicos de origem agroindustrial e urbana aplicados à produção vegetal e fertilidade do solo (Dissertation), Universidade de São Paulo.

Roscoe R, Machado P DA (2002) Fracionamento físico do solo em estudos de matéria orgânica. Embrapa Agropecuária Oeste-Livro técnico (INFOTECA-E).

Salton JC, Mielniczuk J, Bayer C, Boeni M, Conceição PC, Fabrício AC, Broch, DL (2008) Agregação e estabilidade de agregados do solo em sistemas agropecuários em Mato Grosso do Sul. Revista Brasileira de Ciência do Solo 32:11-21.

Stevenson FJ (1994) Humus chemistry: Genesis, composition, reactions. 2.ed. New York, John Wiley \& Sons.

Souza ASD (2012) Fracionamento e estoque de matéria orgânica em diferentes sistemas de manejo no solo no município de IgarapéAçu, no nordeste do Pará (Dissertation), Universidade Federal Rural da Amazônia.

Waksman, SA (1936). Origem do húmus, composição química e importância na natureza. Canoas, Fundação Juquira Candiru. 